\title{
Adrenal-derived 11-oxygenated 19-carbon steroids are the dominant androgens in classic 21-hydroxylase deficiency
}

\author{
Adina F Turcu1, Aya T Nanba1, Robert Chomic², Sunil K Upadhyay', Thomas J Giordano, \\ James J Shields ${ }^{4}$, Deborah P Merke ${ }^{5}$, William E Rainey ${ }^{1,6}$ and Richard J Auchus ${ }^{1,7}$ \\ ${ }^{1}$ Division of Metabolism, Endocrinology and Diabetes, ${ }^{2}$ Michigan Metabolomics and Obesity Center, \\ ${ }^{3}$ Department of Pathology, ${ }^{4}$ Department of Radiology, University of Michigan, $1150 \mathrm{~W}$ Medical Center \\ Drive, Ann Arbor, Michigan, 48109, USA; ${ }^{5}$ Pediatric Services, National Institutes of Health Clinical Center \\ and the Eunice Kennedy Shriver National Institute of Child Health and Human Development, 10 Center \\ Drive, Bethesda, MD, 20892, USA, ${ }^{6}$ Department of Molecular and Integrative Physiology and Medicine \\ and ${ }^{7}$ Department of Pharmacology, University of Michigan, Ann Arbor, Michigan, USA
}

Correspondence should be addressed to Richard J Auchus Email rauchus@med.umich.edu

\begin{abstract}
Objective: To comprehensively characterize androgens and androgen precursors in classic 21-hydroxylase deficiency (21OHD) and to gain insights into the mechanisms of their formation.

Design: Serum samples were obtained from 38 patients ( 19 men) with classic 21OHD, aged 3-59, and 38 sex- and agematched controls; 3 patients with 11 $\beta$-hydroxylase deficiency; 4 patients with adrenal insufficiency; and 16 patients (8 men) undergoing adrenal vein sampling. Paraffin-embedded normal $(n=5)$ and $210 \mathrm{HD}$ adrenal tissues $(n=3)$ were used for immunohistochemical studies.

Methods: We measured 11 steroids in all sera by liquid chromatography-tandem mass spectrometry.

Immunofluroescence localized 3 $\beta$-hydroxysteroid dehydrogenase type 2 (HSD3B2) and cytochrome $b_{5}$ (CYB5A) within the normal and 210HD adrenals.

Results: Four 11-oxygenated 19-carbon (11oxC19) steroids were significantly higher in male and female 21OHD patients than in controls: 11 $\beta$-hydroxyandrostenedione, 11-ketoandrostenedione 11 $\beta$-hydroxytestosterone, and 11-ketotestosterone (3-4-fold, $P<0.0001)$. For $210 \mathrm{HD}$ patients, testosterone and 11-ketotestosterone were positively correlated in females, but inversely correlated in males. All 11 oxC19 steroids were higher in the adrenal vein than in the inferior vena cava samples from men and women and rose with cosyntropin stimulation. Only trace amounts of $110 x C 19$ steroids were found in the sera of patients with 11 $\beta$-hydroxylase deficiency and adrenal insufficiency, confirming their adrenal origin. HSD3B2 and CYB5A immunoreactivities were sharply segregated in the normal adrenal glands, whereas areas of overlapping expression were identified in the $210 \mathrm{HD}$ adrenals. Conclusions: All four 11 oxC19 steroids are elevated in both men and women with classic 21OHD. Our data suggest that 11 oxC19 steroids are specific biomarkers of adrenal-derived androgen excess.
\end{abstract}

\section{Introduction}

Steroid 21-hydroxylase deficiency (21OHD) accounts for the majority of congenital adrenal hyperplasia cases and is one of the most common autosomal recessive diseases (1). As a consequence of the steroid 21-hydroxylase (P450c21, CYP21A2) dysfunction, upstream steroids are diverted
() 2016 European Society of Endocrinology Printed in Great Britain toward androgenic pathways. Severe or classic 21OHD leads to in utero virilization and ambiguous genitalia of affected girls (1). Females with mild or nonclassic 21OHD may present with hirsutism, acne, and irregular menses (2). The excessive adrenal androgen production 
can lead to premature pubarche, rapid somatic growth, advanced bone age, and subfertility in both males and females $(3,4,5,6)$.

Normalization of adrenal androgen synthesis is difficult to achieve (7) without supraphysiological doses of glucocorticoids. Furthermore, reliable biomarkers that accurately distinguish adrenal from gonadal androgen synthesis are lacking, and as a consequence, biochemical targets of disease control are not well defined, especially after the onset of puberty $(8,9)$. Dehydroepiandrosterone (DHEA) and DHEA sulfate (DHEAS), the most abundant 19-carbon $\left(\mathrm{C}_{19}\right)$ steroids produced by the adrenal glands (10), are disproportionally suppressed by glucocorticoid treatment and are not good indicators of hyperandrogenism in classic $21 \mathrm{OHD}(11,12)$. Similarly, there is no good correlation between the routinely measured androgens, androstenedione (AD) and, in women, testosterone (T), and clinical evidence of androgen excess in 21OHD patients $(13,14)$, suggesting that other unrecognized androgens might be produced by the adrenal gland.

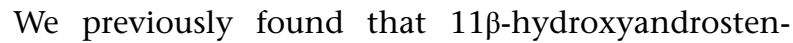
edione (11OHAD) is the most abundant unconjugated $\mathrm{C}_{19}$ steroid in the human adrenal vein blood samples and that its synthesis is adrenocorticotropin (ACTH)-dependent (10). In teleost fishes, 11-ketotestosterone (11KT) is the major androgen, and its synthesis involves the 11ß-hydroxylation of $\mathrm{AD}$ to $11 \mathrm{OHAD}$ with subsequent oxidation and reduction $(15,16)$. Furthermore, $11 \mathrm{KT}$ is a potent agonist of the human androgen receptor (NR3C4), with an affinity comparable to testosterone (10). Given the profound accumulation of testosterone precursors in the adrenal glands of patients with $21 \mathrm{OHD}$, we reasoned that 11oxygenated $\mathrm{C}_{19}$-steroids (11oxC19) might be abundant adrenal products and a major source of active androgens. The goals of the current study were to provide a detailed characterization of the androgens and androgen precursors in classic $21 \mathrm{OHD}$ and to gain insights into the mechanisms and pathways of their formation (Fig. 1A).

\section{Subjects and methods}

\section{Human serum samples}

We enrolled 38 patients with classic 21OHD (19 women), ages 3-59 (Supplemental data file and Supplementary Table 1 , see section on supplementary data given at the end of this article). In 34 of these patients, peripheral serum was obtained during routine clinical visits, while on their usual glucocorticoid replacement (Supplemental data file and Supplementary Table 1). In addition, four samples

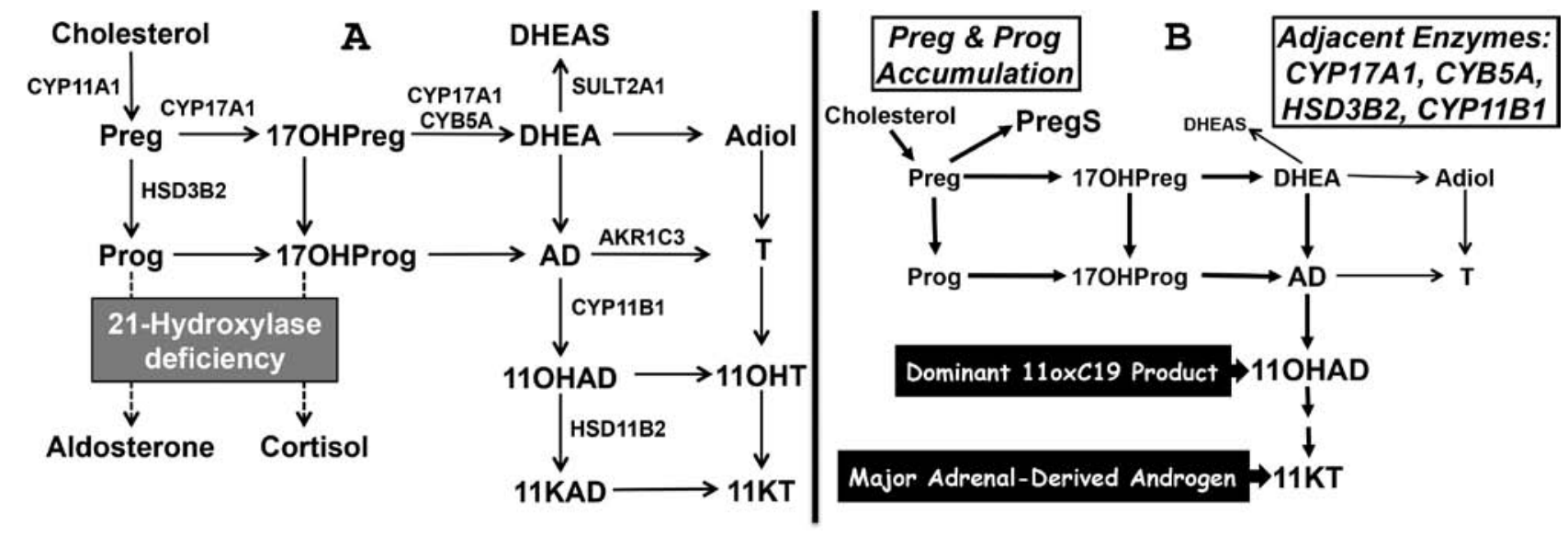

\section{Figure 1}

Pathways of 11-oxygenated 19-carbon (110xC19)-steroid synthesis. (A) Anticipated flux to 11oxC19-steroids resultant from 21-hydroxylase deficiency (21OHD). (B) Observed changes in steroid flux in 21OHD, with upstream precursors shunted to PregS and downstream products metabolized to 110xC19-steroids. STAR, steroidogenic acute regulatory protein; CYP11A1, cholesterol side-chain cleavage; HSD3B2, 3 $\beta$-hydroxysteroid dehydrogenase type 2; CYP17A1, 17 $\alpha$-hydroxylase/17,20-lyase; CYB5A, cytochrome $b_{5}$ type A; CYP11B1, 11 $\beta$-hydroxylase; CYP11B2, aldosterone synthase; AKR1C3, 17 $\beta$-hydroxysteroid dehydrogenase type 5; HSD11B2, 11 $\beta$-hydroxysteroid dehydrogenase, type 2; SULT2A1, sulfotransferase 2A1; Preg, pregnenolone; PregS, Preg sulfate;

Prog, progesterone; 17OHPreg, $17 \alpha$-hydroxypregnenolone; 17OHProg, $17 \alpha$-hydroxyprogesterone; DHEA, dehydroepinandrosterone; DHEAS, DHEA sulfate; Adiol, androst-5-ene-3 $\beta, 17 \beta$-diol; AD, androstenedione; T, testosterone; $110 H A D$,

$11 \beta$-hydroxyandrostenedione, 11KAD, 11-ketoandrostenedione; $11 \mathrm{OHT}$, $11 \beta$-hydroxytestosterone; $11 \mathrm{KT}$, 11-ketotestosterone. 
were obtained at $8 \mathrm{AM}$, before the first morning dose of hydrocortisone, from women with a serum AD greater than $345 \mathrm{ng} / \mathrm{dL}(>12 \mathrm{nmol} / \mathrm{L})$, who had participated in another study (17). Patients who were potentially overtreated with glucocorticoids, as evidenced by a $17 \mathrm{OHP}$ $<20 \mathrm{ng} / \mathrm{dL}$, were excluded. We also enrolled 38 age- and sexmatched controls who were not receiving glucocorticoids, hormonal contraceptives, or chemotherapy. In addition, we obtained peripheral serum from three patients with 11ß-hydroxylase deficiency (11OHD), and four patients with adrenal insufficiency (two with classic 21OHD who underwent bilateral adrenalectomy and two with Addison's disease).

Adrenal vein (AV) samples were obtained as part of standard of care from patients undergoing evaluation for primary aldosteronism. Leftover serum from 16 patients (8 men) with aldosterone-producing adenomas, ages $32-75$, was used for these studies. Only the inferior vena cava (IVC) and AV samples contralateral to the aldosteroneproducing adenoma were used, in order to minimize the influence of dysregulated tumor steroidogenesis on these profiles. The samples were obtained from the IVC and AV before and $20 \mathrm{~min}$ after administration of $0.25 \mathrm{mg}$ bolus cosyntropin. Successful catheterization was confirmed by a minimum AV/IVC cortisol gradient of two at baseline and five after cosyntropin stimulation. All samples were collected under Institutional Review Board (IRB) approved protocols. Written informed consent was granted by all participants who underwent AV sampling, those with $11 \mathrm{OHD}$ and adrenal insufficiency, and 17 patients with 21OHD. A waiver of consent was granted by the IRB for using any leftover serum collected as part of standard clinical care for the control group and 21 of the 21OHD patients.

\section{Steroid quantitation by LC-MS/MS}

Unlabeled and deuterium-labeled steroid standards were obtained from Sigma-Aldrich, Steraloids, Cerilliant, $\mathrm{C} / \mathrm{D} / \mathrm{N}$ Isotopes, and Cambridge Isotope Laboratories or synthesized (Supplementary data file, Steroid synthesis and Supplementary Table 2). A $10-100 \mu \mathrm{L}$ aliquot of serum was deproteinated with $225 \mu \mathrm{L}$ acetonitrile containing 100-200 $\mu \mathrm{L}$ internal standard deuterated steroids at known concentrations, followed by $150 \mu \mathrm{L}$ methanol. The suspension was mixed and centrifuged for $5 \mathrm{~min}$ at $15000 \mathrm{rpm}$. For measurement of 3-keto- $\Delta^{4-5}$ $\left(\Delta^{4}\right.$, such as AD) steroids, the supernatant was mixed with $300 \mu \mathrm{L}$ water and $1 \mathrm{~mL}$ of methyl-t-butyl ether (MTBE) for $4 \mathrm{~min}$. After $10 \mathrm{~min}$, the organic phase was separated and concentrated under nitrogen. For measurement of $3 \beta$-hydroxy- $\Delta^{5-6}\left(\Delta^{5}\right.$, such as DHEA $)$ steroids, a separate aliquot was first extracted with MTBE, dried, resuspended in $50 \mu \mathrm{L} 1 \mathrm{M}$ ammonium hydroxide and $100 \mu \mathrm{L} 1 \mathrm{M}$ hydroxylamine hydrochloride, incubated at $90{ }^{\circ} \mathrm{C}$ for $30 \mathrm{~min}$, and subsequently re-extracted with MTBE and dried as described above. Steroid sulfates were extracted with $1 \mathrm{~mL}$ of 1:1 chloroform:2-butanol from a serum aliquot after mixing with $200 \mu \mathrm{L} 1 \mathrm{M}$ ammonium sulfate. The dried extracts were reconstituted with 100-200 $\mu \mathrm{L}$ of methanol/deionized water (1:1) and transferred to a $0.25 \mathrm{~mL}$ vial insert. Steroids quantitation was performed as previously described (18); Supplementary Table 2 gives the retention times and precursor/product ion pairs for the targeted steroids. The lower limit of detection for each steroid, defined as the minimum concentration achieving an extrapolated signal-to-noise ratio of 3, ranged from 0.8 to $27 \mathrm{ng} / \mathrm{dL}$ (Supplementary Table 2). Intra-assay coefficients of variability (CV) ranged from 2 to $4 \%$ for steroid concentrations $>100 \mathrm{ng} / \mathrm{dL}$ and from $2-11 \%$ for steroid concentrations $<100 \mathrm{ng} / \mathrm{dL}$. Inter-assay $\mathrm{CV}$ ranged from 2 to $8 \%$. The linearity of response was assessed by measuring four separate dilutions per sample $(n=3$ samples), which rendered $r^{2}$ values consistently $>0.95$.

\section{Immunofluorescence analysis}

Paraffin-embedded adrenal glands from patients with 21OHD $(n=3)$ and deceased renal transplant donors without any adrenal pathology $(n=5)$ were obtained under IRB approval. Immunostaining studies were performed using antibodies for human cytochrome $b_{5}$ (CYB5A, mouse monoclonal, Acris) and anti-human 3 3 -hydroxysteroid dehydrogenase type 2 (HSD3B2, also recognizes type 1 isoenzyme) (rabbit polyclonal, kindly provided by CR Parker, University of Alabama at Birmingham) antibodies. For immunofluorescence double-staining, the tissues were incubated with the primary antibody solutions overnight (1:3000 dilution for the CYB5A and 1:1000 dilution for the HSD3B2 antibodies), washed with phosphate-buffered saline, and subsequently incubated with species-specific secondary fluorescent antibodies for $1 \mathrm{~h}$ (Alexa Fluor 488-conjugated anti-mouse and Alexa 594 anti-rabbit dilution 1:100). Immunofluorescence was viewed under an Olympus FV 500 Confocal microscope.

\section{Statistical analysis}

Nonparametric Mann-Whitney $U$ test was applied to compare the 21OHD patients and controls, using GraphPad 
Prism6. Correlation between pairs of steroids was assessed using the nonparametric Spearman's correlation test. A $P<0.05$ was considered to be statistically significant.

\section{Results}

\section{Androgens and androgen precursors in sera of 210HD patients}

Using LC-MS/MS, we performed a targeted analysis of 11 steroids in sera of both $21 \mathrm{OHD}$ patients and controls, including seven unconjugated $\mathrm{C}_{19}$-steroids and four steroid sulfates. The four 110xC19 steroids: 11OHAD, 11-ketoandrostenedione(11KAD), 11ß-hydroxytestosterone (11OHT), and $11 \mathrm{KT}$ were significantly higher in $21 \mathrm{OHD}$ patients as compared with controls (Table 1, 3- to 4-fold, $P<0.0001$ for all). A sub-analysis by sex showed that testosterone was 3.5-fold higher in women with 21OHD $(P<0.0001)$ and, although not statistically significant, lower in men with 21OHD (0.53-fold, $P=0.08)$ as compared with their corresponding sex-matched controls. $\mathrm{AD}$ and all four $110 \mathrm{xC} 19$ steroids were significantly higher in patients with $21 \mathrm{OHD}$ of both sexes as compared with the corresponding controls. Within the 21OHD group, testosterone was higher in males (3.2-fold, $P=0.0003$ ) and $\mathrm{AD}$ was higher in females (2.8-fold, $P=0.01$ ); however, there were no statistically significant differences between males and females for any of the 11oxC19 steroids.

Tight correlations were observed between 11OHAD and $11 \mathrm{KAD}$, as well as $11 \mathrm{OHT}$ and $11 \mathrm{KT}$ in both women ( $r=0.92, P<0.0001$ and $r=0.89, P<0.0001$ respectively) and men $(r=0.89, P<0.0001$ and $r=0.81, P<0.0001$, respectively) (Fig. 2, panels $\mathrm{A}, \mathrm{B}, \mathrm{C}$ and $\mathrm{D}$ ). While 11KAD correlated positively with $\mathrm{AD}$ in both women $(r=0.78$, $P<0.0001)$ and men $(r=0.77, P=0.0001), 11 \mathrm{KT}$ correlated positively with testosterone in women $(r=0.59, P<0.008)$ but negatively, though not significantly, in men $(r=-0.26$, $P=0.27$ ) (Fig. 2, panels E, F, G and H).

DHEA and DHEAS were significantly lower in 21OHD patients than in controls (0.2-fold and 0.1-fold respectively, $P<0.0001)$. Androst-5-ene-3 $\beta, 17 \beta$-diol sulfate was also lower in $21 \mathrm{OHD}$ patients ( 0.1 -fold, $P<0.0001$ ), while pregnenolone sulfate was almost 3-fold higher in 21 OHD patients than in controls $(P=0.001)$. Androst-5ene-3 $\beta, 17 \beta$-diol sulfate correlated tightly with DHEAS in both 21OHD patients $(r=0.96, P<0.0001)$ and controls $(r=0.94, P<0.0001)$. Pregnenolone sulfate also correlated with DHEAS $(r=0.44, P=0.0065$ in 21OHD patients; $r=0.79, P<0.0001$ in controls). These data demonstrate that the precursor steroids upstream of DHEA and DHEAS are diverted to 11 oxC19 and to pregnenolone sulfate in patients with $210 H D$.

\section{Adrenal gland production of $110 x \mathrm{C} 19$ steroids}

To study the origins of 11 oxC19 steroids, we measured these steroids in paired IVC and AV samples from AVS studies, before and after cosyntropin stimulation. We used only AV samples contralateral to an aldosteroneproducing adenoma to minimize deviations from normal adrenal steroid production. Compared with the IVC, the $\mathrm{AV}$ concentrations at baseline were 33-fold higher for 11OHAD, 3.3-fold higher for 11OHT, 2.5-fold higher for $11 \mathrm{KAD}$, and 1.8 -fold higher for $11 \mathrm{KT}$ (Table 2). Cosyntropin stimulation further increased the AV/IVC gradient to 196-fold for 11OHAD, 17-fold for 11OHT,

Table 1 Serum steroid concentrations ( $\mathrm{ng} / \mathrm{dL}$ ). Data are expressed as median (interquartile range). Folds represent the 21OHD/ controls ratio and were calculated using the medians for each steroid.

\begin{tabular}{lcc}
\hline Steroid & $\mathbf{2 1 O H D}(n=38)$ \\
\cline { 1 - 1 } Androstenedione & $155(72-390)$ \\
Testosterone & $80(38-162)$ \\
11 OHAD & $351(188-792)$ \\
$11 \mathrm{KAD}$ & $96(58-143)$ \\
$11 \mathrm{OHT}$ & $59(21-104)$ \\
$11 \mathrm{KT}$ & $171(105-366)$ \\
DHEA & $29(16-85)$ \\
PregS & $10600(3400-25305)$ \\
17 OHPregS & $416(290-1174)$ \\
DHEAS & $18744(7847-64308)$ \\
AdiolS & $2711(1228-9723)$ \\
\hline
\end{tabular}

\begin{tabular}{c}
\hline Controls $(n=38)$ \\
\hline $42(22-63)$ \\
$26(12-309)$ \\
$118(70-154)$ \\
$31(20-42)$ \\
$15(9-21)$ \\
$50(29-78)$ \\
$175(118-318)$ \\
$3738(2853-7769)$ \\
$481(370-683)$ \\
$139784(58409-186697)$ \\
$25576(12095-35882)$ \\
\hline
\end{tabular}

\begin{tabular}{ccc}
\hline Fold & & $\boldsymbol{P}$ \\
\cline { 1 - 1 } 3.7 & & $<0.0001$ \\
3.0 & & 0.09 \\
3.0 & & $<0.0001$ \\
3.1 & & $<0.0001$ \\
4.0 & & $<0.0001$ \\
3.4 & & $<0.0001$ \\
0.2 & & $<0.0001$ \\
2.8 & & 0.001 \\
0.9 & & 0.6 \\
0.1 & & $<0.0001$ \\
0.1 & & $<0.0001$
\end{tabular}

To convert $\mathrm{ng} / \mathrm{dL}$ to $\mathrm{nmol} / \mathrm{L}$, multiply by 0.0347 for testosterone; 0.0349 for androstenedione; 0.0328 for $11 \beta$-hydroxytestosterone (11OHT); 0.0331 for 11 -ketotestosterone (11KT); and 11 $\beta$-hydroxyandrostenedione (11OHAD); 0.0333 for 11-ketoandrostenedione (11KAD); 0.0347 for DHEA; 0.0252 for Pregnenolone sulfate (PregS); 0.0242 for $17 \alpha$-hydroxypregnenolone sulfate (17OHPregS); 0.027 for androst-5-ene-3 $\beta, 17 \beta$-diol sulfate (AdiolS); and 0.0271 for DHEAS. 

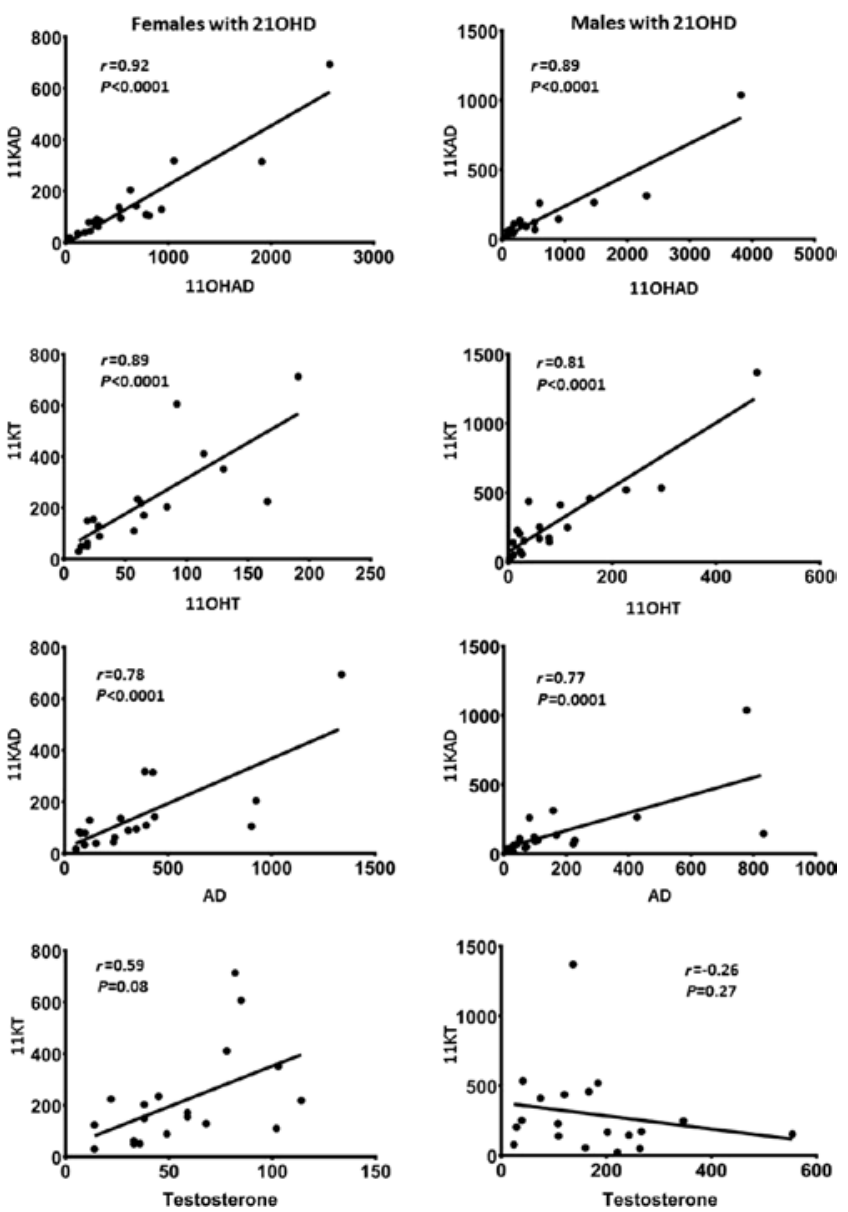

Figure 2

Correlations between serum steroids in men and women with 210HD. Spearman's nonparametric tests were used to analyze correlations between 11 $\beta$-hydroxyandrostenedione (11OHAD) and 11-ketoandrostenedione (11KAD) ( $A$ and $B$ ); between $11 \beta$-hydroxytestosterone (11OHT) and 11-ketotetsosterone $(11 \mathrm{KT})(\mathrm{C}$ and $\mathrm{D})$; between 11KAD and $\mathrm{AD}$ ( $\mathrm{E}$ and $\mathrm{F}$ ); and between $11 \mathrm{KT}$ and testosterone ( $\mathrm{G}$ and $\mathrm{H})$, in women and men with 21-hydroxylase deficiency respectively.

6-fold for 11KAD, and 3.3-fold for 11KT. Following cosyntropin stimulation, the AV concentrations of 11OHAD were augmented 12-fold, those of 11OHT 4.3fold, while those of $11 \mathrm{KAD}$ and $11 \mathrm{KT}$ approximately 2 -fold each. The IVC concentrations for all 11oxC19 steroids were similar between men and women both at baseline, as well as after cosyntropin stimulation. These data indicate that 11OHAD is a major, ACTH-stimulated product of the adrenal gland in men and women, and suggest that $11 \mathrm{OHT}$ is also a minor adrenal product, whereas $11 \mathrm{KAD}$ and $11 \mathrm{KT}$ are primarily peripheral metabolites from their 11 $\beta$-hydroxylated precursors. To confirm that adrenal 11ß-hydroxylase enzymes are responsible for their synthesis, we measured 11 oxC19 steroids in three patients with 11OHD and in four patients with adrenal insufficiency. Only trace amounts of 11OHAD, 11OHT, $11 \mathrm{KAD}$, and $11 \mathrm{KT}$ were found in sera of all seven patients (0-22 ng/dL).

\section{Immunostaining of key enzymes in androgen synthesis in 210HD}

The robust synthesis of 11ß-hydroxylated, 19-carbon, $\Delta^{4}$-steroids in $21 \mathrm{OHD}$ constitutes a paradox, because their synthesis requires enzymes and cofactor proteins segregated to the zona fasciculata (HSD3B2) and zona reticularis (CYB5A) in the normal adrenal. To explain this conundrum, we performed immunohistochemistry for these two key proteins in adrenal glands from patients with 21OHD $(n=3)$ and from deceased renal transplant donors $(n=5)$ with normal adrenal function. Representative images of HSD3B2 and CYB5A immunofluorescence in 21OHD and normal adrenal glands are shown in Fig. 3. In normal adrenal glands, HSD3B2 and CYB5A immunoreactivities are precisely segregated between zona fasciculata and zona reticularis, respectively (Fig. 3A). In contrast, the $21 \mathrm{OHD}$ adrenals exhibited areas containing a mixture of HSD3B2 and CYB5A immunoreactivities (Fig. 3B).

\section{Discussion}

Adrenal androgen excess is a hallmark of 21OHD, but the traditional serum steroid biomarkers, including $\mathrm{AD}$, testosterone, DHEA, and DHEAS, do not serve as consistent, linear indicators of disease severity or treatment response in all patients $(11,13,14)$. Furthermore, DHEAS and AD are not bioactive androgens themselves, but constitute a pool of precursors for potent androgens, such as testosterone and DHT. Previous studies found elevated 11OHAD concentrations in women with nonclassic 21OHD (19, 20, 21). In this study, we have shown that four 11 oxC19 steroids, 11OHAD, 11KAD, 11OHT, and 11KT, are significantly higher in both male and female patients with classic $21 \mathrm{OHD}$ than in age-matched controls. Using in vitro cellbased luciferase reporter systems, we have previously shown that both 11OHT and 11KT activate the human androgen receptor similar to testosterone $(10,22,23)$. Conversely, AD and $11 \mathrm{KAD}$ led to only modest activation of the androgen receptor, and $11 \mathrm{OHAD}$ demonstrated no androgen receptor activation at concentrations up to $1000 \mathrm{nmol} / \mathrm{L}(10,22)$. These data indicate that $11 \mathrm{KT}$ is an important androgen in patients with $21 \mathrm{OHD}$. 
Table 2 Steroid concentrations and ratios in adrenal vein and inferior vena cava serum samples (ng/dL). Concentrations of testosterone, androstenedione (AD), and their 11-oxygenated derivatives in adrenal veins (AV) and inferior vena cava (IVC) of 16 sample sets (8 male), AV/IVC ratios at baseline and following cosyntropin (post-ACTH) stimulation, and fold stimulation.

\begin{tabular}{l}
\hline \\
\hline AV baseline \\
AV post-ACTH \\
IVC baseline \\
IVC post-ACTH \\
AV/IVC baseline \\
AV/IVC post-ACTH \\
Fold stimulation post-ACTH AV \\
Fold stimulation post-ACTH IVC \\
$P$ values, women vs men \\
AV/IVC baseline \\
AV/IVC post-ACTH \\
Fold stimulation post-ACTH AV \\
Fold stimulation post-ACTH IVC
\end{tabular}

\begin{tabular}{c}
\hline 110HT \\
\hline 72 \\
357 \\
15 \\
17 \\
3.3 \\
17 \\
4 \\
1.0 \\
0.3 \\
0.2 \\
0.8 \\
0.4 \\
\hline
\end{tabular}

\begin{tabular}{c}
\hline $\mathbf{1 1 K T}$ \\
\hline 47 \\
112 \\
31 \\
31 \\
1.8 \\
3 \\
2.0 \\
0.9
\end{tabular}

\begin{tabular}{c}
\hline 110HAD \\
\hline 3119 \\
27731 \\
100 \\
146 \\
33 \\
196 \\
12 \\
1.3
\end{tabular}

\begin{tabular}{c}
\hline 11KAD \\
\hline 37 \\
83 \\
15 \\
17 \\
2.5 \\
6 \\
2.4 \\
1.0 \\
0.2 \\
0.2 \\
0.2 \\
0.8
\end{tabular}

\begin{tabular}{cccc}
\hline Testosterone & & $\mathbf{A D}$ \\
\cline { 1 - 1 } 55 & & 375 \\
128 & & 16194 \\
40 & & 29 \\
32 & & 35 \\
1.0 & & 15 \\
5 & & 451 \\
3.4 & & 48 \\
1.0 & & 1.2 \\
& & \\
0.0002 & & 0.6 \\
$<0.0001$ & & 0.6 \\
0.1 & & 0.5 \\
0.8 & & 0.1 \\
\hline
\end{tabular}
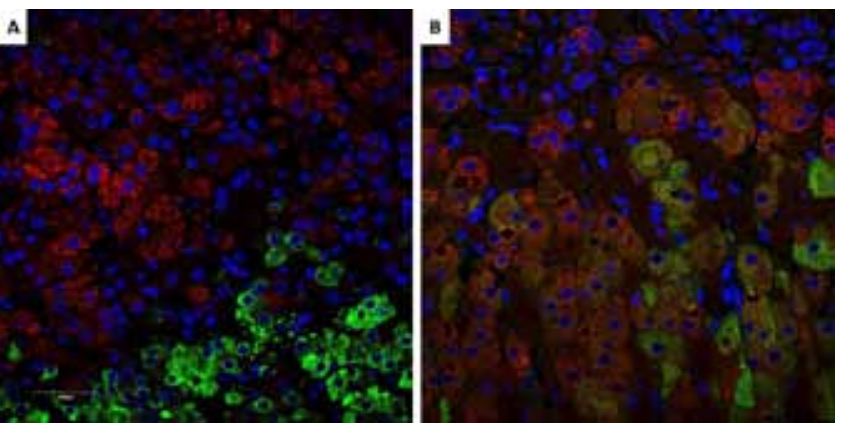

\section{Figure 3}

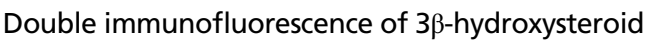
dehydrogenase type 2 (HSD3B2) (red) and cytochrome $b_{5}$ (CYB5A) (green). Nuclei are counterstained in blue. In the normal adrenal gland (A), HSD3B2 and CYB5A are sharply segregated to the zona fasciculata and zona reticularis, respectively, while in the 210HD adrenal (B), areas with intermingled expression of both HSD3B2 and CYB5A were identified.

Unlike $\mathrm{AD}$ and testosterone, which also derive from the gonads, 110xC19 steroid derive primarily from the adrenals and thus strongly reflect the adrenal contribution to the circulating androgens. The synthesis of $11 \mathrm{OHAD}$ occurs predominately in the adrenal gland from $\mathrm{AD}$ (Fig. 1), through the action of steroid 11 $\beta$-hydroxylase (CYP11B1), and small amounts might be produced from cortisol (24). Consistent with previous reports that measured only 11OHAD $(25,26)$, we found negligible amounts of all 11oxC19 steroids in the sera of patients with 11OHD, which confirms that their synthesis relies on CYP11B1. In vitro studies with radiolabeled substrates showed that the ovarian granulosa cells cannot synthesize $11 \mathrm{OHAD}$ from $\mathrm{AD}$ (27). We have previously shown that
11OHAD is the most abundant unconjugated $\mathrm{C}_{19}$ steroid produced by the adrenal glands in women, and that the adrenal was also a source of $11 \mathrm{KAD}, 11 \mathrm{OHT}$, and $11 \mathrm{KT}$ (10). In this study, we extend these findings to show that the adrenal contribution to the circulating $11 \mathrm{OHT}$ and $11 \mathrm{KT}$ pool is similar between men and women, supporting the fact that gonadal testosterone is not an important precursor, if at all, for $11 \mathrm{OHT}$ and $11 \mathrm{KT}$. Furthermore, in our 21OHD males, $11 \mathrm{KT}$ correlated directly and tightly with $11 \mathrm{OHT}$ but tended to correlate inversely with testosterone, as $11 \mathrm{KT}$ will suppress gonadotropins and testosterone production from the testes in men with poorly controlled 21OHD. This latter result suggests that the testosterone/11KT ratio might be an ideal parameter for titrating therapy in men with $21 \mathrm{OHD}$. These findings further suggest that adrenal-derived 11OHT, rather than gonadal-derived testosterone, is the precursor of $11 \mathrm{KT}$. In addition, we found only trace amounts of 11 oxC19 steroids in two 21OHD patients who had undergone adrenalectomy and in two patients with Addison's disease, further supporting the central role of the adrenal in their synthesis. Based on its high AV/IVC gradients and cosyntropin stimulation, our data suggest that 11OHAD is the major direct 11 oxC19 product of the adrenal along with some $11 \mathrm{OHT}$, whereas $11 \mathrm{KAD}$ and $11 \mathrm{KT}$ are primarily formed in peripheral tissues.

DHEAS, the dominant $\mathrm{C}_{19}$ steroid product of the adrenal, is often paradoxically low or low-normal in 21OHD patients even without treatment, thus limiting its clinical utility in these patients (11). Even though we excluded patients with a suppressed 17OHP, we found that DHEA and DHEAS were 6- to 7-fold higher in controls than in $21 \mathrm{OHD}$ patients. The mechanisms underlying this 
phenomenon are poorly understood. Androst-5-ene$3 \beta, 17 \beta$-diol sulfate and DHEAS concentrations varied in parallel, in both $210 H D$ patients and controls. In contrast, $210 H D$ patients produced significantly higher amounts of pregnenolone sulfate as compared with controls (Fig. 1B). Although not as robustly, pregnenolone sulfate correlated directly, rather than inversely, with DHEAS. Combined with the data for $110 x \mathrm{C} 19$ steroids, these results suggest that 21-carbon steroids are diverted along several ordinarily minor pathways in the 210HD adrenal. Several enzymes, including HSD3B2, CYP17A1, CYP11B1, and SULT2A1, compete for these accumulating common substrates. The kinetic interplay between these multiple reactions is difficult to predict and requires further study.

Another intriguing aspect of adrenal steroid biosynthesis is the mechanism by which the production of active androgens becomes sufficient to cause severe virilization in females with 21OHD. For the synthesis of AD and downstream androgens, both HSD3B2 and CYB5A are required. These two key factors in androgens synthesis are co-expressed in the testicular Leydig and ovarian theca cells $(28,29)$. In the normal adrenal gland, HSD3B2 and CYB5A are segregated to the zonae glomerulosa and fasciculata or the zona reticularis, respectively, such that the major adrenal $\mathrm{C}_{19}$ steroids are DHEA and DHEAS. Double-immunohistochemical analysis of HSD3B2 and CYB5A in the normal adrenal glands identified a small number of cells where these two proteins overlap at the interface of the zonae fasciculata and reticularis, which might be responsible for the adrenal $\mathrm{AD}$ and testosterone syntheses (30). Comparison between age groups in this study showed that the co-localization of HSD3B2 and CYB5A is most prominent in 13-20-year-old group, following adrenarche. We hypothesized that the adrenal glands of patients with 21OHD exhibit larger areas of overlapping HSD3B2 and CYB5A expression, which would confer to these cells greater androgenic production efficiency, normally present only in the gonads. Indeed, we found islands of cells with overlapping expression of HSD3B2 and CYB5A in the adrenal glands from patients with classic $210 H D$, but not in normal adrenals (Fig. 3).

Despite a large number of both males and females with matched controls, this initial study of androgens in classic 21OHD has several limitations. Most of our serum samples were obtained randomly, from patients on various glucocorticoid replacement regimens, and accurate clinical assessment of disease control was not possible in many participants. Prospective studies will be needed to assess the correlation of adrenal androgens in 21OHD with the clinical phenotype and response to treatment across the life span. Nevertheless, our data suggest that these 11oxC19 steroids are promising biomarkers of adrenal androgen excess in 21OHD and might be superior to $\mathrm{AD}$ and testosterone. Because $\mathrm{AD}$ and testosterone also derive from the gonads, these traditional biomarker steroids are problematic not only in men but also in women with $21 \mathrm{OHD}$, who often secondarily develop polycystic ovarian syndrome (31). An important strength of our study is the inclusion of both males and females with classic 21OHD. Although clinical stigmata of adrenal androgen excess can be subtle in males, they suffer from sexual precocity $(12,32,33,34)$ and infertility $(4,5,6)$ similar to females. The inclusion of males in both our comparison of $21 \mathrm{OHD}$ with unaffected controls, as well as in our AV analysis, allowed us to conclude that the major source of 11 oxC19 steroids is the adrenal gland.

In summary, we have shown that four 110xC19 steroids are similarly elevated in patients with classic $21 \mathrm{OHD}$ of both sexes. As $11 \mathrm{KT}$ is a potent androgen, it might be the most clinically relevant adrenal-derived androgen in $210 H D$ patients. In addition, our findings suggest that pregnenolone sulfate might serve as an additional biomarker for disease control in patients with 21OHD. With the expanded use of LC-MS/MS, future prospective studies will allow the characterization of steroid biomarkers that accurately reflect disease control and facilitate treatment monitoring.

\section{Supplementary data}

This is linked to the online version of the paper at http://dx.doi.org/10.1530/ EJE-15-1181.

Declaration of interest

The authors declare that there is no conflict of interest that could be perceived as prejudicing the impartiality of the research reported.

\section{Funding}

This work was supported by pilot grants from the University of Michigan Reproductive Sciences Program and by grants MICHR Pilot U046500 to AT, R01GM086596 to RJA, R01DK069950 to WER, and in part by the Intramural Research Program of the NIH. AFT was supported by 1F32DK103461. Mass spectrometry used core services supported by Grant DK089503 from the National Institutes of Health to the University of Michigan under the Michigan Nutrition Obesity Center (NORC).

\section{Acknowledgments}

The authors thank Michelle Vinco and the Molecular Pathology Research Laboratory (Department of Pathology, University of Michigan) for tissue procurement, David Madrigal for serum procurement, and Carole Ramm for regulatory management of clinical research protocols. They thank Janssen Research and Development for returning leftover 
serum samples from study 212082HPL1002 under written informed consent for research purposes.

\section{References}

1 Speiser PW \& White PC. Congenital adrenal hyperplasia. New England Journal of Medicine 2003349 776-788. (doi:10.1002/pbc.25780)

2 Azziz R, Dewailly D \& Owerbach D. Clinical review 56: nonclassic adrenal hyperplasia: current concepts. Journal of Clinical Endocrinology \& Metabolism 199478 810-815. (doi:10.1016/j.fertnstert.2008.06.035)

3 Stikkelbroeck NM, Hermus AR, Braat DD \& Otten BJ. Fertility in women with congenital adrenal hyperplasia due to 21-hydroxylase deficiency. Obstetrical \& Gynecological Survey 200358 275-284.

4 Cabrera MS, Vogiatzi MG \& New MI. Long term outcome in adult males with classic congenital adrenal hyperplasia. Journal of Clinical Endocrinology \& Metabolism 200186 3070-3078. (doi:10.1210/ jcem.86.7.7668)

5 Reisch N, Flade L, Scherr M, Rottenkolber M, Pedrosa Gil F, Bidlingmaier M, Wolff H, Schwarz HP, Quinkler M, Beuschlein F et al. High prevalence of reduced fecundity in men with congenital adrenal hyperplasia. Journal of Clinical Endocrinology \& Metabolism 200994 1665-1670. (doi:10.1210/jc.2008-1414)

6 Claahsen-van der Grinten HL, Otten BJ, Hermus AR, Sweep FC \& Hulsbergen-van de Kaa CA. Testicular adrenal rest tumors in patients with congenital adrenal hyperplasia can cause severe testicular damage. Fertility and Sterility 200889 597-601. (doi:10.1016/j. beem.2008.09.007)

7 Sanchez LA, Moran C, Reyna R, Ochoa T, Boots LR \& Azziz R. Adrenal progestogen and androgen production in 21-hydroxylasedeficient nonclassic adrenal hyperplasia is partially independent of adrenocorticotropic hormone stimulation. Fertility and Sterility 2002 77 750-753. (doi:10.1016/S0015-0282(01)03236-8)

8 Dauber A, Kellogg M \& Majzoub JA. Monitoring of therapy in congenital adrenal hyperplasia. Clinical Chemistry 201056 1245-1251. (doi:10.1373/clinchem.2010.146035)

9 Speiser PW, Azziz R, Baskin LS, Ghizzoni L, Hensle TW, Merke DP Meyer-Bahlburg HF, Miller WL, Montori VM, Oberfield SE et al. Congenital adrenal hyperplasia due to steroid 21-hydroxylase deficiency: an Endocrine Society clinical practice guideline. Journal of Clinical Endocrinology \& Metabolism 201095 4133-4160. (doi:10.1210/ jc.2009-2631)

10 Rege J, Nakamura Y, Satoh F, Morimoto R, Kennedy MR, Layman LC, Honma S, Sasano H \& Rainey WE. Liquid chromatography-tandem mass spectrometry analysis of human adrenal vein 19 -carbon steroids before and after ACTH stimulation. Journal of Clinical Endocrinology \& Metabolism 201398 1182-1188. (doi:10.1210/jc.2012-2912)

11 Rezvani I, Garibaldi LR, Digeorge AM \& Artman HG. Disproportionate suppression of dehydroepiandrosterone sulfate (DHEAS) in treated patients with congenital adrenal hyperplasia due to 21-hydroxylase deficiency. Pediatric Research 198317 131-134. (doi:10.1203/00006450-198302000-00010)

12 Volkl TM, Ohl L, Rauh M, Schofl C \& Dorr HG. Adrenarche and puberty in children with classic congenital adrenal hyperplasia due to 21-hydroxylase deficiency. Hormone Research in Paediatrics 2011 76 400-410. (doi:10.1159/000333696)

13 Speiser PW, Dupont J, Zhu D, Serrat J, Buegeleisen M, Tusie-Luna MT, Lesser M, New MI \& White PC. Disease expression and molecular genotype in congenital adrenal hyperplasia due to 21-hydroxylase deficiency. Journal of Clinical Investigation 199290 584-595. (doi:10.1172/JCI115897)

14 Krone N, Braun A, Roscher AA, Knorr D \& Schwarz HP. Predicting phenotype in steroid 21-hydroxylase deficiency? Comprehensive genotyping in 155 unrelated, well defined patients from southern Germany. Journal of Clinical Endocrinology \& Metabolism 200085 1059-1065. (doi:10.1210/jcem.85.3.6441)
15 Kobayashi M \& Nakanishi T. 11-ketotestosterone induces maletype sexual behavior and gonadotropin secretion in gynogenetic crucian carp, Carassius auratus langsdorfii. General and Comparative Endocrinology 1999115 178-187.

16 Borg B. Androgens in teleost fishes. Comparative Biochemistry and Physiology 1994 109C 219-245.

17 Auchus RJ, Buschur EO, Chang AY, Hammer GD, Ramm C, Madrigal D, Wang G, Gonzalez M, Xu XS, Smit JW et al. Abiraterone acetate to lower androgens in women with classic 21-hydroxylase deficiency. Journal of Clinical Endocrinology \& Metabolism 201499 2763-2770. (doi:10.1210/jc.2014-1258)

18 Turcu AF, Rege J, Chomic R, Liu J, Nishimoto HK, Else T, Moraitis AG, Palapattu GS, Rainey WE \& Auchus RJ. Profiles of 21-carbon steroids in 21-hydroxylase deficiency. Journal of Clinical Endocrinology \& Metabolism 2015100 2283-2290. (doi:10.1210/jc.2015-1023)

19 Huerta R, Dewailly D, Decanter C, Knochenhauer ES, Boots LR \& Azziz R. 11 $\beta$-hydroxyandrostenedione and $\Delta^{5}$-androstenediol as markers of adrenal androgen production in patients with 21-hydroxylase-deficient nonclassic adrenal hyperplasia. Fertility and Sterility 199972 996-1000. (doi:10.1016/S0015-0282(00)00631-2)

20 Hudson RW, Lochnan HA, Danby FW, Margesson LJ, Strang BK \& Kimmett SM. 11ß-hydroxyandrostenedione: a marker of adrenal function in hirsutism. Fertility and Sterility 199054 1065-1071.

21 Carmina E, Stanczyk FZ, Chang L, Miles RA \& Lobo RA. The ratio of androstenedione: 11 $\beta$-hydroxyandrostenedione is an important marker of adrenal androgen excess in women. Fertility and Sterility 199258 148-152.

22 Campana C, Rege J, Turcu A, Pezzi V, Gomez-Sanchez CE, Robins DM \& Rainey WE. Development of a novel cell based androgen screening model. Journal of Steroid Biochemistry and Molecular Biology 2015156 17-22. (doi:10.1016/j.jsbmb.2015.11.005)

23 Storbeck KH, Bloem LM, Africander D, Schloms L, Swart P \& Swart AC. 11ß-hydroxydihydrotestosterone and 11-ketodihydrotestosterone, novel C19 steroids with androgenic activity: a putative role in castration resistant prostate cancer? Molecular and Cellular Endocrinology 2013377 135-146. (doi:10.1016/j.mce.2013.07.006)

24 Axelrod LR, Kraemer DC, Burdett J Jr \& Goldzieher JW. Biosynthesis of $11 \beta$-hydroxyandrostenedione by human and baboon adrenals. Acta Endocrinologica $1973 \mathbf{7 2}$ 545-550.

25 Polson DW, Reed MJ, Franks S, Scanlon MJ \& James VH. Serum $11 \beta$-hydroxyandrostenedione as an indicator of the source of excess androgen production in women with polycystic ovaries. Journal of Clinical Endocrinology \& Metabolism 198866 946-950. (doi:10.1210/jcem-66-5-946)

26 Ibrahim F, Giton F, Boudou P, Villette JM, Julien R, Galons H \& Fiet J. Plasma 11ß-hydroxy-4-androstene-3,17-dione: comparison of a time-resolved fluoroimmunoassay using a biotinylated tracer with a radioimmunoassay using a tritiated tracer. Journal of Steroid Biochemistry and Molecular Biology 200384 563-568. (doi:10.1016/ S0960-0760(03)00077-3)

27 Holownia P, Owen EJ, Conway GS, Round J \& Honour JW. Studies to confirm the source of 11 $\beta$-hydroxyandrostenedione. Journal of Steroid Biochemistry and Molecular Biology 199241 875-880. (doi:10.1016/0960-0760(92)90441-K)

28 Simard J, Ricketts ML, Gingras S, Soucy P, Feltus FA \& Melner MH. Molecular biology of the $3 \beta$-hydroxysteroid dehydrogenase $/ \Delta^{5}-\Delta^{4}$ isomerase gene family. Endocrine Reviews 200526 525-582. (doi:10.1210/er.2002-0050)

29 Dharia S, Slane A, Jian M, Conner M, Conley AJ \& Parker CR Jr. Colocalization of P450c17 and cytochrome b5 in androgensynthesizing tissues of the human. Biology of Reproduction 200471 83-88. (doi:10.1095/biolreprod.103.026732)

30 Nakamura Y, Fujishima F, Hui XG, Felizola SJ, Shibahara Y, Akahira J, McNamara KM, Rainey WE \& Sasano H. 3ßHSD and CYB5A double positive adrenocortical cells during adrenal development/ aging. Endocrine Research 201540 8-13. (doi:10.3109/07435800.201 4.895377) 
31 Barnes RB, Rosenfield RL, Ehrmann DA, Cara JF, Cuttler L, Levitsky LL \& Rosenthal IM. Ovarian hyperandrogynism as a result of congenital adrenal virilizing disorders: evidence for perinatal masculinization of neuroendocrine function in women. Journal of Clinical Endocrinology \& Metabolism 199479 1328-1333. (doi:10.1210/jcem.79.5.7962325)

32 Dacou-Voutetakis C \& Dracopoulou M. High incidence of molecular defects of the CYP21 gene in patients with premature adrenarche. Journal of Clinical Endocrinology \& Metabolism 199984 1570-1574.
33 Oberfield SE, Mayes DM \& Levine LS. Adrenal steroidogenic function in a black and Hispanic population with precocious pubarche. Journal of Clinical Endocrinology \& Metabolism 199070 76-82. (doi:10.1210/ jcem-70-1-76)

34 Balducci R, Boscherini B, Mangiantini A, Morellini M \& Toscano V. Isolated precocious pubarche: an approach. Journal of Clinical Endocrinology \& Metabolism 199479 582-589. (doi:10.1210/ jcem.79.2.8045980)

Received 1 December 2015

Revised version received 21 January 2016

Accepted 9 February 2016 
